\title{
Priming and interference effects can be dissociated in the Stroop task: New evidence in favor of the automaticity of word recognition
}

\author{
ANDRÉS CATENA \\ University of Granada, Granada, Spain \\ LUIS J. FUENTES \\ University of Almería, Almería, Spain \\ and \\ PÍO TUDELA \\ University of Granada, Granada, Spain
}

\begin{abstract}
Recently, Besner, Stolz, and Boutilier (1997) showed that by coloring a single letter instead of the whole word, Stroop interference is reduced or even eliminated, a result that is at odds with the widely accepted assumption that word recognition is automatic. In a replication of the Besner et al. study, we computed priming effects in addition to the standard Stroop interference. Interference results replicated those of Besner et al. Also, negative priming in the all-letter-colored condition and positive priming in the singleletter-colored condition were obtained. Priming findings demonstrate that word processing can take place in the absence of interference effects. These results support the view of automatic processing of words in the Stroop task and call for priming as a more appropriate measure of word processing than interference.
\end{abstract}

Recently, Derek Besner and his colleagues (Bauer \& Besner, 1997; Besner \& Stolz, 1999a, 1999b; Besner, Stolz, \& Boutilier, 1997; Stolz \& Besner, 1999) have reported some experiments that apparently challenge the "automatic" character of word recognition in the Stroop task. The basic underlying idea in their studies is that if the Stroop effect is reduced or even eliminated under certain experimental conditions, this outcome would reasonably question the automatic nature of word processing, because one of the critical features of this kind of processing is that it cannot be prevented even when it is not relevant to the goal task. In their experiments, Besner et al. (1997) nicely show a reduction and even a total elimination of the Stroop effect when color was applied to a single letter instead of to all letters of a word, as is usually the case in the standard version of the task. The authors extended this result when different versions of the Stroop task were used (e.g., Besner \& Stolz, 1999a, 1999b). They account for these results by assuming that subjects used domain-specific processing

This research was supported by Grants PB94-0801 to A.C., PM970002 to L.J.F., and PB95-1153 to P.T., from the Dirección General de Enseñanza Superior e Investigaciones Científicas. We thank Derek Besner, Max Coltheart, and Paloma Marí-Beffa for their many helpful comments. Correspondence should be addressed to A. Catena, Departamento de Psicología Experimental y Fisiología del Comportamiento, Facultad de Psicología, Universidad de Granada, 18071, Granada, Spain (e-mail: acatena@ugr.es). algorithms. Their argument is that if subjects apply a determined algorithm (mental set in their terminology) to process the target (e.g., semantic processing), this algorithm is also used to process the distractor, because it is not possible to activate two different algorithms simultaneously. Now, if both target and distractor belong to the same domain (words), Stroop interference is expected. But if subjects are told to respond to the color or a single letter, it is the mental set (letter processing) that is activated and therefore no semantic processing of the irrelevant word is accomplished, eliminating any Stroop-interference effect.

Elimination of the Stroop effect has also been observed when other variables have been manipulated in Stroop-like tasks. For instance, Fuentes and Ortells (1993) showed that incongruent color words displayed in black and presented in close proximity to a colored central patch produced interference effects, as compared with two baseline conditions (noncolor words and no distractor at all). However, incongruent color words presented far from the central patch did not produce any effect at all. These results are in accord with previous studies that have shown that interference reduces or even disappears as target and distractors become more physically distinct either by increasing eccentricity (e.g., Eriksen \& Eriksen, 1974; Gatti \& Egeth, 1978 ) or by presenting them in different colors (e.g., Francolini \& Egeth, 1980). At first sight, these results do not contradict at all the Besner et al. (1997) idea that word recognition is not automatic; we could simply assume that 
far or dissimilar incongruent stimuli do not produce interference effects because they are perfectly filtered out - that is, they fall outside the focus of attention. Note that this interpretation is in line with the controlled nature of word processing raised by Besner et al. in the Stroop task. However, Fuentes and Ortells also observed that congruent color words produced facilitation effects and that the size of this effect did not change as a function of distractor eccentricity. This means that stimulus words were processed even when they were presented far from fixation, a result that is in accord with our previous studies that have shown semantic priming from parafoveal words presented up to $4^{\circ}$ from fixation (Fuentes, Carmona, Agis, \& Catena, 1994; Fuentes \& Tudela, 1992).

What the findings reported by Fuentes and Ortells (1993) study suggest is that interference is not the only effect that provides a good indication that word processing has taken place. Interference might reflect competition in gaining the response mechanisms - that is, a stage of processing that occurs later on, once stimuli have successfully contacted their representations in the memory system. However, priming might reflect that lexical/semantic analysis has occurred and therefore might be a more appropriate measure to assess the nature of word processing. Literature on priming shows a considerable bulk of evidence favoring the idea that at least a component of semantic priming is automatic (for further evidence, see Fuentes et al., 1994; Fuentes \& Tudela, 1992; Marcel, 1983; Neely, 1977, 1991; Posner \& Carr, 1992; Posner \& Raichle, 1994; Posner, Sandson, Dhawan, \& Shulman, 1989). Why can this automatic component not be involved in the Stroop task too?

If the suggestion above is true, we should be able to find evidence of dissociation between interference and priming effects. Fortunately, we have proof of it. Driver and Tipper (1989) argued that the lack of interference effects either in Eriksen-type paradigms, in which eccentricity is increased, or in Stroop-like tasks, in which target and distractors are made more dissimilar, might reflect that the target-distractor distinction is easier in these cases-that is, that selection of targets against distractors is done more efficiently. However, they claimed that the absence of interference does not necessarily imply that irrelevant distractors are not processed. To demonstrate this, they used Francolini and Egeth's (1980) task within a negative priming paradigm. They replicated the previous findingsthat is, red digits produced interference effects on counting the number of red items, but black digits did not. However, both interfering red and noninterfering black digits produced comparable identity negative priming. The authors extended these results to a word-naming task for pictureword stimuli. Evidence of negative priming from noninterfering distractors has been reported in the literature several times using different tasks (e.g., Allport, Tipper, \& Chmiel, 1985; Tipper, 1985; Yee, 1991).

Given the evidence above, it is hard to conclude that the lack of Stroop interference is equal to the lack of word processing. Note also that in the previously mentioned studies, distractors were usually presented separately from targets, which a priori should foster the filtering out process of distractor stimuli. Despite that, negative priming (Driver \& Tipper, 1989) or Stroop-facilitation effects (Fuentes \& Ortells, 1993) from distractors were found in the absence of Stroop-interference effects.

A recent study by Marí-Beffa, Estévez, and Danziger (2000) provided direct evidence that priming effects are found in the Stroop task. The authors used a similar Stroop task to that used by Besner et al. (1997), but adapted it to a negative priming procedure. That is, trials in the task were arranged so that all-letter-colored probes in trial $n-1$ could be preceded by a single-letter-colored(related or unrelated) prime or by an all-letter-colored (related or unrelated) prime in trial $n$. The results showed that related primes produced negative priming effects on responses to probes irrespective of the prime color level. They argued that Stroop interference and negative priming were to be dissociated in the Stroop task and that the lack of interference effects does not imply lack of processing. However, Marí-Beffa, Estévez, and Danziger (2000) did not observe Stroop-interference effects in both the single-letter-colored and the all-lettercolored conditions. Additionally, when using an XXXX baseline, the authors failed to replicate the reduction of Stroop interference in the single-letter-colored condition.

A more appropriate test to assess the processing of distractor words in the Stroop task, is to replicate Besner et al.'s (1997) Experiment 2, but compute separately those trials in which the to-be-reported color (either when a single letter or the whole word is colored) coincides with the color indicated by the word in the previous trial (the related condition) from those trials in which color and previous word do not coincide (the unrelated condition). Priming effects, in addition to the standard Stroop interference effect, could then be calculated.

The predictions are straightforward. In the all-lettercolored condition, subjects' having to ignore the word on trial $n-1$ would lead to the inhibition of the color word that in the related trials, happens to be the correct response on trial $n$. Because the correct response is inhibited, responding on trial $n$ should be slowed, producing negative priming. In the single-letter-colored condition, if the coloring of a single letter blocks the processing of the word, no priming effect is expected at all. However, if the coloring of a single letter does not prevent the processing of the word, even if it eliminates Stroop interference, negative priming should be found according to Marí-Beffa, Estévez, and Danziger (2000). The results actually showed positive priming, an unexpected result, about which discussion will be postponed until the results are presented.

\section{METHOD}

\section{Subjects}

Sixteen undergraduates from the University of Granada were tested. The subjects received course credit for their participation. All had normal or corrected-to-normal vision.

\section{Stimuli and Apparatus}

The stimuli consisted of four color words (ROJO-red, VERDEgreen, AZUL-blue, and AMARILLO-yellow) and four nonword neutral stimuli that shared with the color words the first two letters (ROTT, 
Table 1

Mean Reaction Times (in Milliseconds) and Percent Error in Word Trials, as a Function of Congruence and Color Level

\begin{tabular}{lccccc}
\hline & \multicolumn{2}{c}{ All Letters Colored } & & \multicolumn{2}{c}{ Single Letter Colored } \\
\cline { 2 - 3 } \cline { 6 - 7 } \multicolumn{1}{c}{ Color Level } & RT & PE & & RT & PE \\
\hline Incongruent & 774 & 18 & & 781 & 17 \\
Neutral & 722 & 18 & & 773 & 17 \\
Stroop interference & 52 & 0 & & 8 & 0 \\
\hline
\end{tabular}

VEQPA, AZKE, and AMPRUSLO). Stimuli were presented in uppercase on the color monitor (VGA card) of an IBM-compatible computer, and subjects' responses were recorded via computer keyboard. On half of the trials, the stimuli were incongruent (the color and the letter string referred to a different color), and on the other half of trials, they were neutral.

\section{Procedure}

The subjects sat approximately $60 \mathrm{~cm}$ from the computer, and the experimenter explained the task verbally to them. Each trial began with the presentation of a single color stimulus in the center of the screen until the subject responded. The subjects were told to ignore the letter string and to respond to the color of the stimulus as quickly and accurately as possible. In order to perform the color responses, they had to press the appropriate color on the computer keyboard: the "z," "x," "n," and "m" keys, which were covered by red, blue, green, and yellow patches, respectively.

On half the trials, the whole stimulus was colored in one of the four colors (the all-letter-colored condition). On the other half of the trials, only a single letter was colored and the remaining letters were presented in white (the single-letter-colored condition). The position of the colored letter was randomly chosen among all positions of the string and was balanced across incongruent and neutral pairings. Each subject carried out three blocks of 384 trials each (the first block was practice), 96 trials in each of the four conditions (allletter-colored vs. single-letter-colored $\times$ incongruent vs. neutral trials). The order of the trials was randomized for each subject. The intertrial interval was $250 \mathrm{msec}$.

\section{RESULTS}

The correct reaction times (RTs) below $150 \mathrm{msec}$ and above $1,800 \mathrm{msec}$ were not included in the data analysis. Less than $1 \%$ of the data were discarded in accordance with this trimming procedure. For the priming analysis, only correct responses to both trial $n-1$ (hereafter, the prime) and trial $n$ (hereafter, the probe) were included.

We conducted two analyses of the data. In the first analysis, we assessed the Stroop-interference effect by comparing the incongruent condition with the neutral condition, as Besner et al. (1997) did. In the second analysis, we assessed the priming effects by comparing the related condition with the unrelated condition.

For both the related and the unrelated conditions, there were two color levels in the prime and two in the probe (i.e., all letters colored vs. a single letter colored). This combination produced four different prime-probe pairs: all-all, all-single, single-all, single-single. Clearly, this analysis makes sense only for trials in which color words are presented. However, because nonwords shared the first two letters with the color words, we performed the priming analyses with these stimuli as well.

\section{Stroop Interference Analysis}

The mean correct RTs and percentage of errors are shown in Table 1 . The data were submitted to a 2 (congruence: incongruent vs. neutral) $\times 2$ (color level: all letters colored vs. single letter colored) repeated measures analysis of variance (ANOVA). The main effect of both congruence and color level were significant $[F(1,15)=9.09$, $M S_{\mathrm{e}}=1,621, p<.01$, and $F(1,15)=15.3, M S_{\mathrm{e}}=908$, $p<.001$, respectively]. Incongruent trials produced longer RTs than did neutral trials (the Stroop effect), and they were also longer in the single-letter-colored than in the allletter-colored condition. Importantly, the congruence $X$ color level interaction was also significant $[F(1,15)=$ $\left.6.908, M S_{\mathrm{e}}=1,092.5, p<.02\right]$. The analysis of the interaction shows that the Stroop effect was observed in the allletter-colored condition $\left[F(1,15)=12.17, M S_{\mathrm{e}}=1,780.63\right.$, $p<.05$ ], but not in the single-letter-colored condition $[F(1,15)<1]$. Error analysis did not produce any significant effect (all $\left.F_{\mathrm{s}}<1\right)$.

\section{Priming Analysis}

The mean correct RTs and percentage of errors for the priming analysis are presented in Table 2 . The random presentation of trials for the 16 subjects resulted in the following distribution of trials across conditions. For the allall combination, there were on average (standard deviations in parentheses) 11.9 (2.26) for related and 25.9 (3.34) for unrelated trials. For the all-single combination, there were 12.3 (2.11) for related and 22.4 (3.74) for unrelated trials. For the single-all combination, there were 13 (3.83) for related and 25.2 (3.23) for unrelated trials. Finally, for the single-single combination, there were 13.5 (2.68) for related and 23.2 (3.64) for unrelated trials. Thus, the number of unrelated trials was twice the number of related trials. Two analyses were carried out, one for words and the other for nonwords.

For words, a 2 (relatedness: related vs. unrelated) $\times 2$ (prime color level: all letters vs. single letter colored) $\times 2$ (probe color level: all letters vs. single letter colored) repeated measures ANOVA was carried out on RTs. The main effects of relatedness, prime-color level, and target-color level failed to reach statistical significance $[F(1,15)<1$; $F(1,15)=4.14, M S_{\mathrm{e}}=8,886.01, p>.05$, and $F(1,15)=$ $3.36, M S_{\mathrm{e}}=6,045.40, p>.05$, respectively]. However, the relatedness $\times$ prime color level interaction proved significant $\left[F(1,15)=11.54, M S_{\mathrm{e}}=2,415.42, p<.01\right]$. The analysis of the simple main effects showed that RTs were longer for the related than for the unrelated condition when all letters were colored in primes $\left[F(1,15)=4.67, M S_{\mathrm{e}}=\right.$ $2,271.48, p<.05]$. However, the reverse pattern occurred when a single letter was colored in primes; that is, RTs were shorter for the related than for the unrelated condition $\left[F(1,15)=4.69, M S_{\mathrm{e}}=870.30, p<.05\right]$. Table 2 shows that this positive priming effect was observed only in the single-all combination, but not in the single-single combination, although this differential effect was not further supported by a relatedness $\times$ prime-color level $\times$ probecolor level significant interaction $\left[F(1,15)=1.6, M S_{\mathrm{e}}=\right.$ 
Table 2

Mean Reaction Times (in Milliseconds) and Percent Error in Word Trials as a Function of Relatedness for All Combinations of Prime and Probe Color Level

\begin{tabular}{|c|c|c|c|c|c|c|c|c|}
\hline \multirow[b]{3}{*}{ Relatedness } & \multicolumn{8}{|c|}{ Pairs } \\
\hline & \multicolumn{2}{|c|}{ All-All } & \multicolumn{2}{|c|}{ All-Single } & \multicolumn{2}{|c|}{ Single-All } & \multicolumn{2}{|c|}{ Single-Single } \\
\hline & RT & $\overline{\mathrm{PE}}$ & RT & $\overline{\mathrm{PE}}$ & $\overline{\mathrm{RT}}$ & $\overline{\mathrm{PE}}$ & RT & $\overline{\mathrm{PE}}$ \\
\hline Related & 935 & 8 & 906 & 6 & 852 & 7 & 863 & 7 \\
\hline Unrelated & 899 & 10 & 869 & 10 & 907 & 11 & 853 & 9 \\
\hline Priming & -36 & 2 & -37 & 4 & 55 & 4 & -10 & 2 \\
\hline
\end{tabular}

Note-All, all letters colored. Single, a single letter colored. The first position in the pair is for primes, and the second for probes.

$5,034.27, p>.22]$. Neither the remaining interactions on RTs nor the error analysis produced any statistically significant effect.

Separate analyses were carried out on nonwords presented either in the prime or in the probe. Not one of these analyses proved significant, either for RTs or for errors.

\section{DISCUSSION}

The present experiment replicated the results reported by Besner et al. (1997, Experiment 2). Interference from incongruent trials was dramatically reduced up to the point of being eliminated when a single letter, instead of all letters, was colored in the Stroop task. Importantly, this result was practically identical to that reported by Besner et al., even though we used 768 experimental trials and 16 subjects, and Besner et al. (Experiment 2) used 144 trials and 64 subjects. This suggests that the elimination of the Stroop effect in the single-letter-colored condition is a robust effect. However, when trials were arranged so that they allowed us to assess priming effects in the very similar task to that used by Besner et al., a clearcut picture emerged. Negative priming was found when all letters were colored, a result that replicated that of Marí-Beffa, Estévez, and Danziger (2000). But, contrary to Marí-Beffa et al., priming was positive when a single letter was colored. Note that Marí-Beffa et al. showed negative priming in this condition. However, the authors arranged prime and probe displays so that probes always contained all letters colored and preceded half the trials by single-letter-colored and half by all-letter-colored trials. This higher proportion of all-letter-colored with respect to single-letter-colored trials could have produced a bias toward the processing of the word in all trials, favoring inhibition processes being applied even in the single-lettercolored condition. In contrast, we found positive priming in the absence of Stroop interference and negative priming when interference was observed. Importantly, the fact that no priming effects were found with nonwords indicates that priming in this experiment reflects that words were processed at least up to a lexical/semantic level.

The dissociation between Stroop interference and priming observed in this experiment supports the contention that both effects tap different stages of processing. Priming reflects the success of a stimulus to activate its repre- sentation in memory and, therefore, that the stimulus has been recognized. On the other hand, interference might reflect competition in gaining the control of action, a stage of processing that occurs once competing stimuli have been fully processed. In contrast to what Besner and his colleagues seemed to argue, interference in the Stroop task is not always an appropriate measure for assessing whether or not word recognition has taken place. In the Stroop task, facilitation effects from congruent/related stimuli seem to be a better index of that kind of processing (Fuentes \& Ortells, 1993, and the present experiment).

Importantly, the dissociation between priming and Stroop interference suggests that the proposed mental set hypothesis raised by Besner and his colleagues to account for the reduction/elimination of Stroop interference, affects a stage of processing once word recognition has taken place. Mental set might not affect the specific algorithm of processing that the subject is going to apply, but whether or not inhibition is going to be applied to activated representations from distractors. This account is in line with that of Marí-Beffa, Fuentes, Catena, and Houghton (2000; see also Marí-Beffa, Houghton, Estévez, \& Fuentes, 2000) in accounting for the elimination of semantic priming in the prime task. Here, the authors found that when the subjects were told to search for a single letter in the prime display, semantic priming from the target stimulus vanished compared with when the subjects were told to make a lexical decision response. However, distractor words presented simultaneously with the target did produce priming effects. The mental set, or whatever other mechanism is assumed, did not prevent the distractor words from being semantically processed.

One issue of theoretical relevance is how to account for the occurrence of positive and negative priming and how these effects relate to the amount of Stroop interference observed as a function of color level. In regard to negative priming, the effect was observed only when primes were composed of all letters colored - that is, in both the allall and the all-single combinations (see Table 2). Importantly, the effect was similar in both cases (36 and $37 \mathrm{msec}$, respectively). Note that the episodic retrieval account of negative priming (Neill, Valdes, Terry, \& Gorfein, 1992) cannot account for these results because it predicts more negative priming when the episode's retrieval is facilitated-for example, by increasing prime-probe 
similarity. It happens in the all-all combination where primes and probes are composed of all letters colored, but not in the all-single combination. A different account assumes that, when all letters in primes were colored, attention was allocated to the word level, producing high activation of the prime word representation. Thus, negative priming might be the result of inhibition being applied to a very salient distractor, the prime word, that can strongly compete with color for the control of the response. The consequence of such a competition is Stroop interference. An activation-inhibition account of negative priming of the type proposed by Houghton and Tipper (1994; see also Houghton, Tipper, Weaver, \& Shore, 1996) is better supported by the present results. According to that model, inhibition would occur after the offset of the prime, but before the onset of the probe. The offset of the prime would bring about an inhibitory rebound that produces negative priming in responses to probes.

Contrary to negative priming, positive priming emerged only when primes were composed of a single letter colored, but the effect was modulated by the kind of probe that followed the prime. If the probe contained all letters colored (single-all combination), a large positive priming effect was observed (see Table 2). If the probe contained a single letter colored (single-single combination), there was no priming at all. One explanation for the lack of priming in the single-single combination is to assume that when attention is allocated at the letter level, processing of the distractor word is blocked (Besner et al., 1997). This could explain the lack of Stroop interference when a single letter was colored, but not the large positive priming found in the single-all combination.

An alternative account is to assume that when attention is allocated to the letter level, activation produced by the prime words reflected only automatic processing. The orthographic disruption produced by an unfamiliar display (a mixed-color display) might have slowed activation of prime-word representation to a degree that prevented it from interfering with color response in the prime display. ${ }^{1}$ When all letters were colored in the next trial (single-all combination), the return of attention to the word level might have increased activation of the prime word through a backward priming mechanism (see Neely, 1991, for evidence of this). As a consequence, a large positive priming effect was observed. Because in the single-single combination attention does not return to the word level in probes, backward priming might not have taken place and, therefore, a rather weak vanishing-with-timeautomatic activation was not enough to produce priming effects. Thus, according to our account, positive priming in the singleletter-colored condition was the product of two components: an automatic component that could be delayed by the unfamiliar configuration in the prime, ${ }^{2}$ and a controlled component that was initiated once attention was allocated to the word level in the probe display. The idea that semantic priming can reflect the action of two components is not new and has been proposed in previous re- search (Fuentes et al., 1994; Fuentes \& Tudela, 1992; Neely, 1977; Posner \& Raichle, 1994; Posner et al., 1989; Posner \& Snyder, 1975).

The automaticity of word recognition is further demonstrated in studies that have used modern neuroimaging techniques. For instance, Price, Wise, and Frackowiak (1996) presented their subjects with four types of stimuli: real words, pseudowords, consonant letter strings, and false fonts. Subjects were engaged in a nonlinguistic feature-detection task that required the determination of whether the stimulus had one or more ascenders. Even though word recognition was not required by the task and ascender detection did not require subjects to attend to the whole stimulus (like in the present single-letter-colored condition), words activated the brain areas that form part of the left hemisphere language network.

Further studies that combine behavioral and neuroimaging data in the Stroop task might lead to more conclusive evidence about the automaticity of word recognition.

\section{REFERENCES}

Allport, D. A., Tipper, S. P., \& Chmiel, N. R. J. (1985). Perceptual integration and post-categorical filtering. In M. I. Posner \& O. S. M. Marin (Eds. ). Attention and performance XI (pp. 107-132). Hillsdale, NJ: Erlbaum.

Bauer, B., \& Besner, D. (1997). Processing in the Stroop task: Mental set as a determinant of performance. Canadian Journal of Experimental Psychology, 51, 61-68.

Besner, D., \& Stolz, J. A. (1999a). Context dependency in Stroop paradigm: When are words treated as nonlinguistic objects? Canadian Journal of Experimental Psychology, 53, 374-380.

Besner, D., \& Stolz, J. A. (1999b). Unconsciously controlled processing: The Stroop effect reconsidered. Psychonomic Bulletin \& Review, 6, 449-455.

Besner, D., Stolz, J. A., \& Boutilier, C. (1997). The Stroop effect and the myth of automaticity. Psychonomic Bulletin \& Review, 4, 221-225.

Driver, J., \& TipPER, S. P. (1989). On the nonselectivity of "selective" seeing: Contrasts between interference and priming in selective attention. Journal of Experimental Psychology: Human Perception \& Performance, 15, 304-314.

ERIKSEN, B. A., \& ERIKSEN, C. W. (1974). Effects of noise letters upon the identification of a target letter in a nonsearch task. Perception \& Psychophysics, 16, 143-149.

Francolini, C. M., \& Egeth, H. E. (1980). On the nonautomaticity of "automatic" activation: Evidence of selective seeing. Perception \& Psychophysics, 27, 331-342.

Fuentes, L. J., Carmona, E., Agis, I. F., \& Catena, A. (1994). The role of the anterior attention system in semantic processing of both foveal and parafoveal words. Journal of Cognitive Neuroscience, 6, 17-25.

Fuentes, L. J., \& ORTElls, J. J. (1993). Facilitation and interference effects in a Stroop-like task: Evidence in favor of semantic processing of parafoveally-presented stimuli. Acta Psychologica, 84, 213-229.

Fuentes, L. J., \& TudELA, P. (1992). Semantic processing of foveally and parafoveally presented words in a lexical decision task. Quarterly Journal of Experimental Psychology, 45A, 299-322.

Gatti, S. V., \& Egeth, H. E. (1978). Failure of spatial selectivity in vision. Bulletin of the Psychonomic Society, 11, 181-184.

Houghton, G., \& Tipper, S. P. (1994). A model of inhibitory mechanisms in selective attention. In D. Dagenbach \& T. H. Carr (Eds.), Inhibitory processes in attention, memory, and language (pp. 53-112). San Diego: Academic Press.

Houghton, G., Tipper, S. P., Weaver, B., \& Shore, D. I. (1996). Inhibition and interference in selective attention: Some tests of a neural network model. Visual Cognition, 3, 119-164. 
Marcel, A. J. (1983). Conscious and unconscious perception: Experiments on visual masking and word recognition. Cognitive Psychology, 15, 197-237.

Marí-Beffa, P. Estévez, A. F., \& Danziger, S. (2000). Stroop interference and negative priming: Problems with inferences from null results. Psychonomic Bulletin \& Review, 7, 499-503.

Marí-Beffa, P., Fuentes, L. J., Catena, A., \& Houghton, G. (2000). Semantic priming in the prime task effect: Evidence of automatic semantic processing of distractors. Memory \& Cognition, 28, 635-647.

Marí-Beffa, P., Houghton, G., Estévez, A. F., \& Fuentes, L. J. (2000). Word-based grouping affects the prime-task effect on semantic priming. Journal of Experimental Psychology: Human Perception \& Performance, 26, 469-479.

Neely, J. H. (1977). Semantic priming and retrieval from lexical memory: Roles of inhibitionless spreading activation and limited-capacity attention. Journal of Experimental Psychology: General, 3, 226-254.

Neely, J. H. (1991). Semantic priming effects in visual word recognition: A selective review of current findings and theories. In D. Besner \& G. W. Humphreys (Eds.), Basic processes in reading: Visual word recognition (pp. 264-336). Hillsdale, NJ: Erlbaum.

Neill, W. T., Valdes, L. A., Terry, K. M., \& Gorfein, D. S. (1992). Persistence of negative priming: II. Evidence for episodic trace retrieval. Journal of Experimental Psychology: Learning, Memory, \& Cognition, 18, 993-1000.

Posner, M. I., \& CARr, T. H. (1992). Lexical access and the brain: Anatomical constraints on cognitive models of word recognition.American Journal of Psychology, 105, 1-26.

Posner, M. I., \& RAichle, M. E. (1994). Images of mind. New York: Scientific American Library.
Posner, M. I., Sandson, J., Dhawan, M., \& Shulman, G. L. (1989). Is word recognition automatic? A cognitive-anatomical approach. Journal of Cognitive Neuroscience, 1, 50-60.

Posner, M. I., \& SNyder, C. R. R. (1975). Attention and cognitive control. In R. L. Solso (Ed.). Information processing and cognition: The Loyola Symposium (pp. 55-85). Hillsdale, NJ: Erlbaum.

Price, C. J., Wise, R. J. S., \& Frackowiak, R. S. J. (1996). Demonstrating the implicit processing of visually presented words and pseudowords. Cerebral Cortex, 6, 62-70.

Stolz, J. A., \& Besner, D. (1999). On the myth of automatic semantic activation in reading. Current Directions in Psychological Science, $\mathbf{8}$, 61-65.

TIPPER, S. P. (1985). The negative priming effect: Inhibitory effects of ignored primes. Quarterly Journal of Experimental Psychology, 37A, 571-590.

YEE, P. L. (1991). Semantic inhibition of ignored words during a figure classification task. Quarterly Journal of Experimental Psychology, 43A, 127-153.

\section{NOTES}

1. We thank Max Coltheart for suggesting this.

2. The fact that automatic activation can be delayed for an unfamiliar display would argue against a strong form of automatic word recognition.

(Manuscript received March 16, 2000; revision accepted for publication April 20, 2001.) 